\title{
Interrelations Between Virtual-World and Real-World Activities: Comparison of Genders, Age Groups, and Pathological and Nonpathological Internet Users
}

\author{
Fatih Bayraktar, Ph.D., and Hasan Amca, Ph.D. ${ }^{2}$
}

\begin{abstract}
After the Internet Revolution, people have started to spend most of their everyday time online carrying out virtual activities. A limited number of studies tried to answer whether virtual activities match our real-world (RW) activities. Moreover, to our knowledge, there was no study that dealt with these interrelations between virtual and RW activities among the pathological and nonpathological users of the Internet (i.e. PIUs and NPIUs). The primary aim of this study was to fill this gap and to investigate the correlations between virtualworld (VW) and RW activities among PIUs and NPIUs. The secondary aim was to examine the perceptions of the Internet and motivations to go online for PIUs and NPIUs. The third aim was to compare virtual and RW activities across gender and age groups. The results indicated that correlations between most of the activities in RW and VW were high among men and women, among age groups, and also among PIUs and NPUs. However, beyond these similarities, perceptions of the Internet and motivations to browse into VW were differed among PIUs and NPIUs. In other words, PIUs, but not NPIUs, perceived VW activities more gratified and had motivations to go online for gratified functions.
\end{abstract}

\section{Introduction}

I

N THE LAST QUARTER OF THE 20TH CENTURY, the popularity of the Internet has resulted in dramatic changes, transforming societies into networked communities whose members spend a significant proportion of their daily lives in virtual environments. As a result, virtual world (VW) has penetrated into the real world (RW), and the clear boundary between RW and VW has begun to fade. This might result in transfer of behaviors gained in $\mathrm{RW}$ to $\mathrm{VW}^{1,2}$ or vice versa. ${ }^{3}$ In other words, the behaviors in RW and VW might be the parts of a continuum.

A significant amount of work in the literature showed that the activities in RW and VW were interrelated. For example, the research on bullying-cyberbullying and online-offline aggression indicated that these behaviors were correlated to each other. ${ }^{4-6}$ Moreover, offline victims were found to be online victims. ${ }^{7,8}$ Beyond these problematic behaviors, social networks in RW and offline friendships seem to continue in VW. ${ }^{9,10}$ Based on this information, our study aimed to find the interrelations between a series of activities in VW and RW by comparing age and gender groups and also pathological and nonpathological Internet users (i.e., PIUs and NPIUs). We used a correlational method that was supposed to be most suitable one for the purposes of our study to analyze the interrelations. Significant correlations were hypothesized as an indication of continuity VW activities in RW or vice versa.

\section{Age differences in VW and RW activities}

The relationship between VW and RW activities may differ across age groups. To our knowledge, two studies partially addressed this issue. Both studies focused on age-based differences in task performances in VW activities. ${ }^{11,12}$ However, no research was found to address the correlation between VW and RW activities in different age groups.

RQ1: Are VW and RW activities correlated with each other in different age groups?

\section{Gender differences in VW and RW activities}

A number of studies have focused on gender differences in task performance in VW activities. Some of these studies have found no gender differences in given tasks, ${ }^{13}$ whereas others have favored men in activities such as mental rotation. ${ }^{14,15}$ In addition to these, a few studies have tested gender difference in VW activities. Results indicated that women were more likely to use the Internet for interpersonal communication, ${ }^{16}$

Department of ${ }^{1}$ Psychology and ${ }^{2}$ Electrical and Electronic Engineering, Eastern Mediterranean University, Famagusta, Turkey. 
and in parallel to that, the VW activities of women include firmer and more widespread social relationships. ${ }^{17}$ Gender differences have also emerged in the motivation for entering VW activities with women favoring socially oriented motives. ${ }^{18}$ However, there were studies that found no gender gap in Internet activities. ${ }^{19}$ To our knowledge, however, no research has explored gender differences in the relationship between VW and RW activities.

RQ2: Are VW and RW activities correlated with each other across genders?

\section{VW and RW activities among PIUs and NPIUs}

The Internet can be a gateway between RW and VW activities depending on the aim and motivation of the user. Repeatedly searching for online gratification may transform the Internet users into PIUs if this search for satisfaction becomes a habit. ${ }^{20}$ In other words, if people seek interaction, entertainment, and relaxation in the VW rather than RW, these VW activities may increase the risk of becoming pathological user.

Pathological Internet Use has been used to describe a series of problematic behaviors and their results related to gratifying VW activities. A number of scales have been developed to diagnose PIU in recent years such as Internet Addiction Test (IAT), ${ }^{21}$ Generalized Problematic Internet Use Scale (GPIUS), ${ }^{22}$ Online Cognition Scale (OCS), ${ }^{23}$ or Internet Addiction Scale for Taiwanese (IAST). ${ }^{24}$ We chose to use IAT in our research for two reasons. First, IAT met the purposes of our study following Chang and Man Law's confirmatory factor analysis, which extracted three dimensions of IAT, namely, withdrawal and social problems, time management and performance, and reality substitute. ${ }^{25}$ The items under these dimensions were supposed to discriminate PIUs and NPUs in terms of their VW and RW activities, motivations to enter VW, and perceptions of VW. Second, IAT was already adapted to Turkish and proved as a valid and reliable measurement tool in Turkish-speaking samples. ${ }^{26-28}$

Empirical findings showed that being active in VW was associated with being a PIU. For example, Song et al. showed that membership in a virtual community was strongly related with being a PIU. ${ }^{29}$ Another study showed that PIUs prefer interactive applications on the Internet much more than NPIUs. ${ }^{30}$ To our knowledge, however, the interrelations between VW and RW activities among PIUs and NPIUs in a wide range of subjects have not been studied enough to yield a satisfactory conclusion.

RQ3: Are VW and RW activities correlated with each other across PIUs and NPIUs?

The essence of our research was to find out whether the perceptions of VW and motivations to enter VW differed between PIUs and NPIUs. A limited number of studies found out that PIUs perceived the Internet more gratifying (i.e., entertaining, interesting, exciting, etc.) and have stronger motivations for gratifications than NPIUs. ${ }^{31-33}$ However, these studies used a limited number of variables to derive a sound conclusion. Therefore, the proposed work focused on this issue by using a wide range of variables. The age and gender were also controlled as two demographic variables that might be related with PIU while conducting the analyses, since the previous research indicated that men and younger age groups were more prone to use the Internet pathologically. ${ }^{34-36}$

H1: PIU will be predicted more strongly by VW activities than RW activities.

H2: PIUs will perceive VW activities more gratified than NPIUs.

H3: PIUs will have higher motivations to enter VW for gratified functions than NPIUs.

\section{Materials and Methods \\ Participants}

A total of 540 people participated in an Internet survey (325 women and 211 men, 4 nonreported) from two Turkishspeaking regions (North Cyprus and Turkey). Six age groups were considered (below 18 years of age, $n=122 ; 18-25$, $n=236 ; 26-35, n=137 ; 36-45, n=18 ; 46-55, n=21 ; 55$ and over, $n=6)$. The last three age groups were omitted from the further analyses because of small sample sizes. These small numbers might be a result of decreasing Internet use rates in later stages of life or reluctance to complete the survey in these age groups.

\section{Measures}

Second Life Survey (New Media Consortium, 2007). Twenty questions about RW and VW activities inspired by the Second Life Survey were chosen (sample item: I generally dance in RW-I generally dance in VW). The reliability coefficient for the entire scale, for RW activities, and for VW activities was $0.83,0.81$, and 0.72 , respectively.

Characteristics of Second Life Scale. This 10-item scale was designed to evaluate the characteristics of second life ( $1=$ not at all, $5=$ exactly). We expanded the instructions by including other VW facilities, including Facebook and online games (sample item: I associate with the interactive characteristics of VW facilities). The reliability coefficient was 0.74 .

Motivation Scale. This 17-item scale was designed to evaluate motivations for entering second life $(1=$ not at all, $5=$ exactly). We expanded the instructions, as in the Characteristics of Second Life Scale (Sample item: I enter the VW to have fun). The reliability coefficient was 0.87 .

Internet Addiction Test. This scale was developed to evaluate PIU. It includes 20 items on a six-point scale $(0=$ never, $5=$ always). For this survey, the reliability coefficient was 0.89 (sample item: I neglect household chores to spend more time online). Participants were classified as PIUs if their scores were one standard deviation over the mean score ( $n=90,16.7$ percent). Participants were grouped into PIUs and NPUs, and all statistical comparisons were based on this dichotomous variable.

\section{Procedures}

This Internet survey was distributed to participants by using social networks. First a number of key persons from various age groups were identified and asked recommending their contacts to complete the survey voluntarily by giving 
the link. This method is called snowball sampling and found to be a reliable technique to have representative samples. ${ }^{37}$ All the participants were given code numbers to protect the anonymity.

\section{Results}

To achieve the goals of the study, correlations between RW and VW activities across age groups, genders, and PIUNPIUs; predictor role of RW and VW activities for PIU; and comparison of PIUs and NPIUs in terms of perception of and motivations to enter VW activities were analyzed separately. Fisher's $r$-to-z $z$ transformations were used to assess the significance of difference between two correlation coefficients when interrelations were compared. A confidence interval on the difference between two independent correlations was also computed. These were indicated by as $z$ value (See Tables 1-4). Hierarchical regression analysis was conducted to test the predictor roles of RW and VW activities over PIU. Regression analysis was used to assess the relationship between one dependent variable (i.e., PIU) and several independent variables (i.e., RW and VW activities). On the other hand, Hierarchical regression analysis allowed us to control the effects of demographic variables (i.e., age and gender) over PIU in the first step and analyze the predictor roles of independent variables in the second step. Finally, the Independent-Samples $t$ test was conducted to analyze whether the difference in perceptions of VW between PIUs and NPIUs was significantly different from zero or not.

\section{Correlations between RW and VW activities}

For all participants, the relationship between VW and RW activities resulted in very high correlation coefficients with the exception of "meeting new people"; the correlation between shopping in RW and VW was low $(r=0.18)$ (see Table 1).

The correlations between RW and VW activities were also high for gender and age groups, with the exception of meeting new people (see Tables 2 and 3). Analyses showed that the correlations between RW and VW shopping and dancing were stronger among men than among women (see Table 2). For the analysis of age group differences, the cor-

Table 1. The Correlations Between Real-World and Virtual-World Activities

\begin{tabular}{lc} 
Activity in RW and VW & $\begin{array}{c}\text { Correlation } \\
\text { coefficient }\end{array}$ \\
\hline Random browsing & $0.26^{* *}$ \\
Meeting new people & 0.06 \\
Listening to presentations, lectures, or talks & $0.36^{* *}$ \\
Participating in formal meetings & $0.25^{* *}$ \\
Building things & $0.30^{* *}$ \\
Entertaining & $0.48^{* *}$ \\
Shopping & $0.18^{* *}$ \\
Attending music/art performances & $0.47^{* *}$ \\
Dancing & $0.30^{* *}$ \\
Participating in communities & $0.43^{* *}$ \\
\hline
\end{tabular}

${ }^{* *} p<0.001$.

RW, real world; VW, virtual world. relation between RW and VW entertainment for the youngest age group was stronger than the older groups. Similarly, the correlation between attending music/art performances in RW and in VW was stronger for the youngest age group (see Table 3).

\section{RW and VW activities for PIUs and NPIUS}

The correlations between RW and VW activities among both PIUs and NPIUs were high, except meeting new people (see Table 4). Difference in shopping activity in RW and in VW was nonsignificant for PIUs $(r=0.18)$. However, the significance of correlation coefficients was influenced by sample size. Therefore, we suggested that shopping behavior in RW and VW was not significantly different for PIUs and NPIUs. $z$ Values showed that the correlation coefficient between attending music/art performances in RW and in VW was stronger for PIUs than for NPIUs.

\section{$R W$ and VW activities as predictors of PIU}

In the first step of hierarchical regression analyses, analysis of variance results showed that age and gender were significant predictors of PIU $[F(2,36)=20.864, p<0.001]$. The results showed that men and younger age groups were more tended to PIU. In the second step, where RW and VW activities were entered, the model was also significant $[F(22,536)=9.746$, $\left.p<0.001 ; R^{2}=0.36, \Delta R^{2}=0.26, p<0.001\right]$. The results indicated that random browsing in both RW and VW predicted PIU. Furthermore, meeting new people, entertaining, attending music/art performances, dancing, and participating in gettogethers in VW, and entertaining and attending music/art performances in RW significantly (but negatively) predicted PIU (see Table 5). Overall, greater involvement in VW activities and less involvement in entertaining and social RW activities were found to be related to higher PIU scores.

\section{Perception of VW for PIUs and NPIUs}

Independent samples t-test results showed that perceptions of VW differed significantly between PIUs and NPIUs (see Table 6). Overall, PIUs perceived VW as more engaging, interactive, realistic, social, funny, educational, and inspiring than NPIUs did.

\section{Motivations for entering VW for PIUs and NPIUs}

Independent samples $t$ test results showed that motivations for entering VW differed significantly between PIUs and NPIUs (see Table 7). Overall, PIUs entered VW more frequently than NPIUs for gratified functions.

\section{Discussion}

The present study aimed to answer whether VW and RW activities correlated with each other for different age and gender groups, and also when PIUs and NPIUs are compared. We hypothesized that PIU would be predicted by VW activities rather than RW ones; also PIUs would perceive VW activities more gratified and would have more motivations to enter VW for gratified functions than NPIUs.

The overall correlations between VW and RW activities were mostly significant and positive. This general pattern was consistent with the results of similar studies that showed 
Table 2. The Correlations Between Real-World and Virtual-World Activities for Gender Groups

\begin{tabular}{|c|c|c|c|}
\hline Activity in $R W$ and $V W$ & $\begin{array}{l}\text { Correlation coefficient } \\
\text { for women }(\mathrm{n}=325)\end{array}$ & $\begin{array}{l}\text { Correlation coefficient } \\
\text { for men }(\mathrm{n}=211)\end{array}$ & $\begin{array}{c}\mathrm{z} \text { Value (significance } \\
\text { of the difference between } \\
\text { two correlational coefficients) }\end{array}$ \\
\hline Random browsing & $0.24^{* *}$ & $0.29^{* *}$ & $-0.6(p=0.27)$ \\
\hline Meeting new people & 0.07 & 0.09 & ns \\
\hline Listening to presentations, lectures, or talks & $0.35^{* *}$ & $0.41^{* *}$ & $-0.8(p=0.21)$ \\
\hline Participating in formal meetings & $0.23^{* *}$ & $0.32^{* *}$ & $-1.1(p=0.14)$ \\
\hline Building things & $0.33^{* *}$ & $0.31^{* *}$ & $0.25(p=0.40)$ \\
\hline Entertaining & $0.47^{* *}$ & $0.49^{* *}$ & $-0.29(p=0.39)$ \\
\hline Shopping & $0.18^{* *}$ & $0.30^{* *}$ & $-2.58(p<0.005)$ \\
\hline Attending music/art performances & $0.47^{* *}$ & $0.50^{* *}$ & $-1.38(p=0.08)$ \\
\hline Dancing & $0.22^{* *}$ & $0.46^{* *}$ & $-3.08(p<0.001)$ \\
\hline Participating in communities & $0.39 * *$ & $0.49^{* *}$ & $-1.4(p=0.08)$ \\
\hline
\end{tabular}

$$
\text { ** } p<0.0001 \text {. }
$$

an interrelation between online and offline behaviors. ${ }^{4-10}$ In other words, we may suppose that RW and VW activities that we studied are the parts of a continuum that our participants behave similarly while they're online or offline.

Similar significant correlations were found between RW and VW activities for different age groups. However, when the strength of correlation coefficients was compared, the relationship between entertaining and attending music/art performances in RW and VW activities was stronger for the youngest age group than for older ones. This finding might be because participants in the youngest group were more open to entertainment and attending music/art performances in both RW and VW environments. Because this study was the first of its kind to address the interrelations between VW and RW activities in different age groups, these results could not be compared to previous findings. Therefore, future studies have to be carried out to re-visit this issue with various samples and age groups.

The relationship between RW and VW activities was also significant when men and women were compared. Results indicated that the correlations between shopping and dancing in RW and VW were stronger for men than for women. This result might indicate that the women in our sample preferred shopping and dancing in RW more than in VW, parallel to gender roles in everyday life. However, inconsistent with previous studies, ${ }^{16-18}$ women and men showed similar social communication abilities (e.g., participating in communities and attending music/art performances) in RW and VW environments. This finding may be the result of increasingly similar socialization processes of men and women. Consistent to our result, the recent findings showed that the gender gap between men and women was narrowing in VW. ${ }^{19}$

RW and VW activities were also related to each other for PIUs and NPIUs. When the strength of the correlation coefficients was compared, the only significant difference was between attending music/art performances in RW and VW, and the correlation coefficient was stronger for PIUs. Further analysis through hierarchical regression indicated that attending music/art performances in VW and attending music/art performances in RW predicted PIU positively and negatively in respect. Therefore, we suggested that attending music/art performances in VW and RW predicted PIU differently despite a strong, positive correlation between them.

The only nonsignificant $z$ value for all comparisons was between meeting new people in RW and VW. This result could be justified in two ways. First, this might be because of a nonlinear relationship between meeting new people in RW and VW for all participants without regard for their gender, age group, or PIU versus NPIU status. Second, as distinct from other interrelations, this result might show a discontinuity for meeting new people in RW and VW. In other words, the participants might prefer to meet new people virtually

Table 3. The Correlations Between Real-World and Virtual-World Activities for Age Groups

\begin{tabular}{|c|c|c|c|c|c|}
\hline Activity in $R W$ and $V W$ & $\begin{array}{l}\text { Correlation coefficient } \\
\text { for below } 18(\mathrm{n}=122)\end{array}$ & & $\begin{array}{l}\text { Correlation coefficient } \\
\text { for } 18-25(\mathrm{n}=236)\end{array}$ & & $\begin{array}{l}\text { Correlation coefficient } \\
\text { for } 26-35(\mathrm{n}=137)\end{array}$ \\
\hline Random browsing & $0.24^{* *}$ & & $0.22^{* *}$ & & $0.29^{* *}$ \\
\hline Meeting new people & 0.16 & & -0.02 & & 0.16 \\
\hline $\begin{array}{l}\text { Listening to presentations, } \\
\text { lectures, or talks }\end{array}$ & $0.33^{* *}$ & & $0.32^{* *}$ & & $0.35^{* *}$ \\
\hline Participating in formal meetings & $0.40^{* *}$ & \multirow{3}{*}{$\mathrm{z}=4.81, \mathrm{p}<.001$} & $0.26^{* *}$ & & $0.24^{* *}$ \\
\hline Building things & $0.41^{* *}$ & & $0.33^{* *}$ & & $0.25^{* *}$ \\
\hline Entertaining & $0.73^{* *}$ & & $\rightarrow 0.37^{* *}$ & & $0.46^{* *}$ \\
\hline Shopping & $0.24^{* *}$ & \multirow[t]{2}{*}{$\mathrm{z}=2.73, \mathrm{p}<.001$} & $0.15^{*}$ & $\mathrm{z}=3.43, \mathrm{p}<.001$ & $0.16^{*}$ \\
\hline Attending music/art performances & $0.66^{* *}<$ & & $0.45^{* *}$ & $\mathrm{z}=2.84, \mathrm{p}<.002$ & \\
\hline Dancing & $0.36^{* *}$ & & $0.22 * *$ & & $\begin{array}{l}0.41^{* *} \\
0.37^{* *}\end{array}$ \\
\hline Participating in communities & $0.45^{* *}$ & & $0.46^{* *}$ & & $0.38^{* *}$ \\
\hline
\end{tabular}

${ }^{* *} p<0.001,{ }^{*} p<0.05$. 
Table 4. The Correlations Between Real-World AND VirTUAL-WORLd ACTIVITIES FOR PATHOLOGICAL INTERNET USERS AND NONPATHOLOGICAL USERS

\begin{tabular}{|c|c|c|c|}
\hline $\begin{array}{l}\text { Activity in } \\
R W \text { and } V W\end{array}$ & $\begin{array}{l}\text { Correlation } \\
\text { coefficient } \\
\text { (PIUs) } \\
(\mathrm{n}=90)\end{array}$ & $\begin{array}{c}\text { Correlation } \\
\text { coefficient } \\
\text { (NPUs) } \\
(\mathrm{n}=446)\end{array}$ & $\begin{array}{c}\mathrm{z} \text { Value } \\
\text { (significance of } \\
\text { the difference } \\
\text { between two } \\
\text { correlational } \\
\text { coefficients) }\end{array}$ \\
\hline Random browsing & $0.25^{* *}$ & $0.23^{*}$ & $0.18(p=43)$ \\
\hline $\begin{array}{l}\text { Meeting new } \\
\text { people }\end{array}$ & 0.09 & 0.08 & ns \\
\hline $\begin{array}{l}\text { Listening to } \\
\text { presentations, } \\
\text { lectures, or talks }\end{array}$ & $0.41^{* *}$ & $0.34^{* *}$ & $0.70(p=0.24)$ \\
\hline $\begin{array}{l}\text { Participating } \\
\text { in formal } \\
\text { meetings }\end{array}$ & $0.29^{* *}$ & $0.27^{* *}$ & $0.19(p=0.43)$ \\
\hline Building things & $0.29 * *$ & $0.34^{* *}$ & $-0.47(p=0.32)$ \\
\hline Entertaining & $0.58^{* *}$ & $0.45^{* *}$ & $1.52(p=0.06)$ \\
\hline Shopping & 0.18 & $0.18^{* *}$ & $0(p=0.50)$ \\
\hline $\begin{array}{l}\text { Attending music/ } \\
\text { art performances }\end{array}$ & $0.65^{* *}$ & $0.46^{* *}$ & $2.37(p<0.001)$ \\
\hline Dancing & $0.27^{*}$ & $0.32^{* *}$ & $-0.47(p=0.32)$ \\
\hline $\begin{array}{l}\text { Participating } \\
\text { in communities }\end{array}$ & $0.47^{* *}$ & $0.40^{* *}$ & $0.74(p=0.23)$ \\
\hline
\end{tabular}

${ }^{* *} p<0.001,{ }^{*} p<0.05$.

PIU, pathological Internet users; NPU, nonpathological users.
Table 6. T-Test Results for Perception of Virtual World: COMPARISON OF NONPATHOlOgical UsERS and Pathological Internet Users

\begin{tabular}{llc}
\hline Perception of $V W$ & \multicolumn{1}{c}{ Mean (SD) } & $\mathrm{t}(d f)$ \\
\hline Engaging & NPUs 2.74 (1.17) & $-4.65(450), p<0.0001$ \\
& PIUs 3.39 (1.17) & \\
Interactive & NPUs 3.33 (1.22) & $-4.70(450), p<0.0001$ \\
& PIUs 3.99 (1.12) & \\
Realistic & NPUs 2.41 (1.05) & $-2.14(453), p<0.05$ \\
& PIUs 2.68 (1.19) & \\
Social & NPUs 3.01(1.19) & $-2.79(454), p<0.01$ \\
& PIUs 3.41 (1.19) & \\
Funny & NPUs 3.42 (1.01) & $-5.91(459), p<0.0001$ \\
& PIUs 4.11 (0.98) & \\
Educational & NPUs 2.38 (1.07) & $-3.33(448), p<0.0001$ \\
Inspiring & PIUs 2.82 (1.22) & \\
& NPUs 2.08 (1.11) & $-5.27(445), p<0.0001$ \\
& PIUs 2.79 (1.23) &
\end{tabular}

$S D$, standard deviation.

rather than physically. A number of studies showed consistent results supporting this proposition. ${ }^{32-34}$

Consistent with Hypothesis 1, our findings indicated that PIU was mainly predicted by VW activities positively and by some of RW activities negatively (except random browsing). Moreover, the results showed that men and younger age groups were more inclined to be PIUs. In other words, being

Table 5. Hierarchical Regression Analysis of Pathological Internet Usage Score for Real-World and Virtual-World Activities Controlling Gender and Age

\begin{tabular}{|c|c|c|c|c|c|c|}
\hline \multirow[b]{2}{*}{ Variables } & & \multicolumn{2}{|c|}{ Unstandardized coefficients } & \multirow[b]{2}{*}{$\beta$} & \multirow[b]{2}{*}{$\mathrm{t}$} & \multirow[b]{2}{*}{$\mathrm{p}$ Value } \\
\hline & & Beta & Standardized error & & & \\
\hline Gender & & -6.52 & 1.25 & -0.25 & -5.23 & $0.000^{* * *}$ \\
\hline Age & & -2.96 & 0.73 & -0.19 & -4.04 & $0.000^{* * *}$ \\
\hline Gender & & -4.19 & 1.24 & -0.16 & -3.38 & $0.001^{* *}$ \\
\hline Age & & -1.53 & 0.72 & -0.09 & -2.12 & $0.035^{*}$ \\
\hline Random & VW & 2.36 & 0.49 & 0.22 & 4.79 & $0.000^{* * * *}$ \\
\hline browsing & RW & 1.49 & 0.49 & 0.13 & 3.04 & $0.003^{* *}$ \\
\hline \multirow[t]{2}{*}{ Meeting new people } & VW & 1.38 & 0.57 & 0.12 & 2.43 & $0.016^{*}$ \\
\hline & RW & -0.29 & 0.62 & -0.03 & -0.47 & 0.641 \\
\hline \multirow[t]{2}{*}{ Listening to presentations, lectures, or talks } & VW & -0.04 & 0.57 & -0.01 & -0.07 & 0.944 \\
\hline & RW & -0.83 & 0.65 & -0.07 & -1.27 & 0.202 \\
\hline \multirow[t]{2}{*}{ Participating in formal meetings } & VW & -1.12 & 0.65 & -0.09 & -1.72 & 0.085 \\
\hline & RW & 0.50 & 0.61 & 0.05 & 0.82 & 0.414 \\
\hline \multirow[t]{2}{*}{ Building things } & VW & 0.82 & 0.53 & 0.09 & 1.54 & 0.124 \\
\hline & RW & 0.39 & 0.57 & 0.04 & 0.69 & 0.494 \\
\hline \multirow[t]{2}{*}{ Entertaining } & VW & 1.69 & 0.54 & 0.17 & 3.15 & $0.002^{* *}$ \\
\hline & RW & -1.37 & 0.70 & -0.12 & -1.98 & $0.049^{*}$ \\
\hline \multirow[t]{2}{*}{ Shopping } & VW & 0.018 & 0.48 & 0.01 & 0.04 & 0.970 \\
\hline & RW & 0.38 & 0.57 & 0.04 & 0.66 & 0.508 \\
\hline \multirow[t]{2}{*}{ Attending music/art performances } & VW & 1.18 & 0.55 & 0.12 & 2.15 & $0.032^{*}$ \\
\hline & RW & -1.11 & 0.59 & -0.11 & -1.88 & 0.062 \\
\hline \multirow[t]{2}{*}{ Dancing } & VW & 1.12 & 0.47 & 0.12 & 2.37 & $0.018^{*}$ \\
\hline & RW & -0.07 & 0.71 & -0.01 & -0.09 & 0.923 \\
\hline \multirow[t]{2}{*}{ Participating in communities } & VW & 1.54 & 0.57 & 0.15 & 2.68 & $0.008^{* *}$ \\
\hline & RW & -0.65 & 0.52 & -0.07 & -1.25 & 0.213 \\
\hline
\end{tabular}

${ }^{*} p<0.05,{ }^{* *} p<0.01,{ }^{* * *} p<0.001$.

Variables and values in bold show the first step of the Hierarchical Regression Analysis. 
Table 7. T-Test Results for Motivations for Entering Virtual World: Comparison of NonPathological Users AND PATHOLOGICAl INTERNET Users

\begin{tabular}{|c|c|c|}
\hline $\begin{array}{l}\text { Motivations } \\
\text { for entering } V W\end{array}$ & Mean (SD) & $\mathbf{t}(d f)$ \\
\hline Having fun & $\begin{array}{l}\text { NPUs } 3.36 \text { (1.17) } \\
\text { PIUs } 3.98 \text { (1.14) }\end{array}$ & $-4.52(454), p<0.0001$ \\
\hline Making friends & $\begin{array}{l}\text { NPUs } 2.04 \text { (1.12) } \\
\text { PIUs } 2.68 \text { (1.34) }\end{array}$ & $-4.67(447), p<0.0001$ \\
\hline $\begin{array}{l}\text { Doing something } \\
\text { that cannot be } \\
\text { done in real } \\
\text { world }\end{array}$ & NPUs 1.48 (0.92) & $-4.04(444), p<0.0001$ \\
\hline Passing time & $\begin{array}{l}\text { PIUs } 1.95(1.21) \\
\text { NPUs } 3.42(1.16) \\
\text { PIUs } 4.08(1.01)\end{array}$ & $-4.96(453), p<0.0001$ \\
\hline $\begin{array}{l}\text { Adding meaning } \\
\text { to life }\end{array}$ & PIUs 3.03 (1.19) & $-4.52(454), p<0.0001$ \\
\hline Earning money & $\begin{array}{l}\text { NPUs } 1.16(0.62) \\
\text { PIUs } 1.32(0.79)\end{array}$ & $-2.04(441), p<0.05$ \\
\hline $\begin{array}{l}\text { Experiencing } \\
\text { sexual pleasure }\end{array}$ & $\begin{array}{l}\text { NPUs } 1.22(0.71) \\
\text { PIUs } 1.57(1.06)\end{array}$ & $-3.69(443), p<0.0001$ \\
\hline Feeling excited & $\begin{array}{l}\text { NPUs } 1.74(1.07) \\
\text { PIUs } 2.52(1.21)\end{array}$ & $-5.98(442), p<0.0001$ \\
\hline $\begin{array}{l}\text { Improving } \\
\text { social skills }\end{array}$ & $\begin{array}{l}\text { NPUs } 2.18(1.18) \\
\text { PIUs } 2.87 \text { (1.33) }\end{array}$ & $-4.79(442), p<0.0001$ \\
\hline $\begin{array}{l}\text { Improving } \\
\text { cognitive skills }\end{array}$ & $\begin{array}{l}\text { NPUs } 2.00 \text { (1.17) } \\
\text { PIUs } 2.59 \text { (1.33) }\end{array}$ & $-4.14(444), p<0.0001$ \\
\hline $\begin{array}{l}\text { Improving } \\
\text { physical skills }\end{array}$ & $\begin{array}{l}\text { NPUs } 1.50(.89) \\
\text { PIUs } 1.89 \text { (1.15) }\end{array}$ & $-3.40(441), p<0.001$ \\
\hline $\begin{array}{l}\text { Experimenting } \\
\text { with roles }\end{array}$ & $\begin{array}{l}\text { NPUs } 1.36(0.80) \\
\text { PIUs } 1.83(1.01)\end{array}$ & $-4.72(441), p<0.0001$ \\
\hline $\begin{array}{l}\text { Relieving } \\
\text { boredom in } \\
\text { real world }\end{array}$ & NPUs 2.03 (1.17) & $-5.81(444), p<0.0001$ \\
\hline Dating & $\begin{array}{l}\text { NPUs } 1.29(0.68) \\
\text { PIUs } 1.87(1.14)\end{array}$ & $-6.16(441), p<0.0001$ \\
\hline $\begin{array}{l}\text { Overcoming } \\
\text { barriers in } \\
\text { real world }\end{array}$ & NPUs 1.54 (.93) & $-5.60(441), p<0.0001$ \\
\hline
\end{tabular}

male, younger, and a random browser both in RW and in VW (as well as other VW activities) increased the risk of PIU. The result related with age and gender was consistent with previous research findings. ${ }^{30-32}$ The relationship between random browsing in RW and PIU might occur because those who perceive their life as aimless might be prone to PIU.

Our findings showed that PIUs perceived VW activities more gratified and had higher motivations for entering VW related for gratified functions. These results were consistent to Hypotheses 2 and 3 and indicated that Uses and Gratifications Theory ${ }^{33}$ was applicable for explaining the cognitive background of PIU. Accordingly, our findings can be used in the preparation of cognitively based treatment programs for PIU.
Despite this promising set of findings, our study was not free from limitations. First, our research was based on an Internet survey, and all the disadvantages of this research method also pertained to our study. For example, participants did not have the opportunity to get feedback on questions. Furthermore, we could not administer the questionnaires related to RW and VW activities in two separate sessions. This might have inflated the correlations. Second, our analyses depended on self-reported data. Therefore, the results were not free from self-report bias. Third, this study was based on correlations. Because of this, the interrelations between RW and VW activities can not be interpreted as transfers from one context to another but only the parts of a continuum. Therefore, there is a need for future experimental studies to provide stronger evidence for the causal relations underlying our findings. Fourth, we used a global score from IAT. However, using three dimensions of this test (see Chang and Law, 2008 for more detail) as dependent variable and to re-analyze the findings whether VW and RW will differ according to the dimensions can enrich the literature related with PIU. Also, the analyses must be retested by using other diagnostic tools to measure PIU, which was mentioned previously. Each measurement tool focuses on different characteristics of PIU. Therefore, replicating our study with these tools may validate our results. Lastly, for the sake of the completeness, our findings can be re-analyzed in non-Turkish-speaking sample populations. Despite these limitations, our study provided a first glimpse into the relationship between VW and RW activities across age groups, genders, and PIUs versus NPIUs, and our findings provided an important foundation for further studies.

\section{Disclosure Statement}

No competing financial interests exist.

\section{References}

1. Garcia-Rodriguez O, Ferrer-Garcia M, Pericot-Valverde I, et al. Identifying specific cues and contexts related to smoking craving for the development of effective virtual environments. CyberPsychology \& Behavior, and Social Networking 2011; 14:91-97.

2. Huvaila I, Holmberg K, Stefan EK, Widen-Wulff G. Social capital in second life. Emerald Online Information Review 2010; 34:295-316.

3. Kohler T, Matzler K, Füller J. Avatar-based innovation: using virtual worlds for real-world innovation. Technovation 2009; 29:395-407.

4. Hinduja S, Patchin JW. Bullying, cyberbullying, and suicide. Archives of Suicide Research 2010; 14:206-221.

5. Riebel J, Jager RS, Fischer UC. Cyberbullying in Germanyan exploration of prevalence, overlapping with real life bullying and coping strategies. Psychology Science Quarterly 2009; 51:293-314.

6. Liu EZF, Ho HC, Song YJ. Effects of an online rational emotive curriculum on primary school student tendencies for on-line and real-world aggression. The Turkish Online Journal of Educational Technology 2011; 10:83-93.

7. Katzer C, Fetchenhauer D, Belschak F. Cyberbullying: who are the victims?: a comparison of victimization in internet chatrooms and victimization in school 2009; 21:25-36.

8. Erdur-Baker, Ö. Cyberbullying and its correlation to traditional bullying, gender and frequent and risky usage of in- 
ternet-mediated communication tools. New Media \& Society 2010; 12:109-125.

9. Subrahmanyam K, Reich SM, Waechter N, et al. Online and offline social networks: use of social networking sites by emerging adults. Journal of Applied Developmental Psychology 2008; 29:420-433.

10. Valkenburg PM, Peter J. Preadolescents' and adolescents' online communication and their closeness to friends. Developmental Psychology 2007; 43:267-277.

11. Mager R, Stefani O, Angehrn I, et al. Neurophysiological age differences during task-performance in a stereoscopic virtual environment. Applied Psychophysiology and Biofeedback 2005; 30:233-238.

12. Rose NS, Rendell PG, McDaniel MA, et al. Age and individual differences in prospective memory during a "virtual week": the roles of working memory,vigilance,task regularity, and cue focality. Psychology of Aging 2010; 25:595-605.

13. Parsons TD, Larson P, Kratz K, et al. Sex differences in mental rotation and spatial rotation in a virtual environment. Neuropsychologia 2004; 42:555-562.

14. Castelli L, Corazzini LL, Geminiani GC. Spatial navigation in large-scale virtual environments: gender differences in survey tasks. Computers in Human Behavior 2008; 24:16421667.

15. Tlauka M, Brolese A, Pomeroy D, et al. Gender differences in spatial knowledge acquired through simulated exploration of a virtual shopping centre. Journal of Environmental Psychology 2005; 25:111-118.

16. Weiser E. Gender differences in Internet use patterns and Internet application preferences: a two-sample comparison. CyberPsychology and Behavior 2010; 4:167-178.

17. Yee N. Motivations of play in online games. CyberPsychology and Behavior 2006; 9:772-775.

18. Yee N. The demographics, motivations and derived experiences of users of massively-multiuser online graphical environments. PRESENCE: Teleoperators and Virtual Environments 2006; 15:309-329.

19. Shaw LH, Gant LM. Users Divided? Exploring the gender gap in Internet use. CyberPsychology \& Behavior 2002; 5:517-527.

20. Marlatt GA, Baer JS, Donovan, DM, et al. Addictive behaviors: etiology and treatment. Annual Review of Psychology 1988; 39:223-252.

21. Young, KS. Internet addiction: the emergence of a new clinical disorder. Cyberpsychology \& Behavior.1996; 1:237-244.

22. Caplan SE. Problematic Internet use and psychological wellbeing:development of a theory-based cognitive-behavioral measurement instrument. Computers in Human Behavior 2002; 18:553-575.

23. Davis RA, Flett GL, Besser A. Validation of a new scale for measuring problematic Internet use: implications for preemployment screening. CyberPsychology \& Behavior 2002; 5:331-345.
24. Lin SSJ, Tsai CC. Sensation seeking and internet dependence of Taiwanese high school adolescents. Computers in Human Behavior 2002; 18:411-426.

25. Chang MK, Law SPM. Factor structure of Young's Internet Addiction Test: a confirmatory study. Computers in Human Behavior 2008; 24:2597-2619.

26. Bayraktar F, Gun, Z. Incidence and correlates of Internet usage among adolescents in North Cyprus. CyberPsychology \& Behavior 2007; 10:191-197.

27. Iskender M, Akın A. Self-compassion and Internet addiction. Turkish Online Journal of Educational Technology 2011; 10:215-221.

28. Batigun $\mathrm{AD}$, Kilic N. The relationships between Internet addiction, social support, psychological symptoms and some socio-demographical variables 2011; 26:1-13.

29. Song I, Larose R, Eastin MS, et al. Internet gratifications and internet addiction: on the uses and abuses of new media. CyberPsychology \& Behavior 2004; 7:384-394.

30. Whang LS, Lee S, Chang G. Internet over-users' psychological profiles: a behavior sampling analysis on internet addiction. CyberPsychology \& Behavior 2003; 6:143-150.

31. Chou C, Hsiao MC. Internet addiction, usage, gratification, and pleasure experience: The Taiwan college students' case. Computers \& Education 2000; 35:65-80.

32. Yang SC, Tung CJ. Comparison of Internet addicts and nonaddicts in Taiwanese high school. Computers in Human Behavior 2007; 23:79-96.

33. Swanson DL. Gratification seeking, media exposure, and audience interpretations: some directions for research. Journal of Broadcasting and Media 1987; 31:237-254.

34. Sherer K. College life online: healthy and unhealthy Internet use. Journal of College Student Development 1997; 38:655-665.

35. Morahan-Martin JM, Schumacher P. Incidence and correlates of Pathological Internet Use. Computers in Human Behavior 16:13-29.

36. Brenner V. Psychology of computer use: XLVII. Parameters of Internet use, abuse and addiction. The first 90 days of the Internet usage survey. Psychological Reports 1997; 80:879_ 882.

37. Lopes CS, Rodrigues LC, Sichieri R. The lack of selection bias in a snowball sampled case-control study on drug abuse. International Journal of Epidemiology 1996; 25: 1267-1270.

Address correspondence to: Dr. Fatih Bayraktar Department of Psychology Eastern Mediterranean University Famagusta-North Cyprus via Mersin 10 Turkey

E-mail: fatih.bayraktar@emu.edu.tr 